\title{
Bemiparin versus Enoxaparin in the Prevention of Venous Thromboembolism among Intensive Care Unit Patients
}

\author{
Mohamed Sayed Abbas \\ Department of Anesthesia, Faculty of Medicine, Ain Shams University, Cairo, Egypt
}

\section{Abstract}

Background: Critically ill patients are considered a high-risk group for developing venous thromboembolism (VTE). Due to their impaired cardiopulmonary reserve, these VTEs may result in significant morbidity and mortality. In this study, we compared two types of low molecular weight heparin, enoxaparin, and bemiparin, as regards to their efficacy and safety in VTE prevention among Intensive Care Unit (ICU) patients. Methods: This study was a prospective, randomized trial of 100 critically ill patients who are at high risk for developing VTE were included in this study and assigned to receive subcutaneous injections of either 3500 international units (IU) anti-factor Xa of bemiparin sodium or 40 mg of enoxaparin given once a day and patient were followed for 60 days after initiation of anticoagulant therapy for the development of documented deep venous thrombosis (DVT) using bilateral lower limb venous duplex, documented pulmonary embolism using computed tomography pulmonary angiography, and complications related to injectant anticoagulant. Results: Confirmed DVT was observed in two patients (4\%) in the bemiparin group compared with 10 patients $(20 \%)$ in the enoxaparin group with $P<0.05$. Confirmed pulmonary embolism (PE) was observed in seven patients $(14 \%)$ in the enoxaparin group with no recorded cases of confirmed PE in the bemiparin group $(P<0.05)$. No deaths were recorded in either group. Adverse events such as ecchymosis or hematoma at the injection site were observed in one patient (2\%) in the bemiparin group and eight patients $(16 \%)$ in the enoxaparin group $(P<0.05)$. There was no significant statistical difference between both groups as regards other adverse effects and complications related to the injectant anticoagulant. Conclusion: Bemiparin was superior to enoxaparin as a prophylactic anticoagulant for VTE in critically ill patients with less adverse local complications at the injection site. The study was registered on www.clinicaltrials.gov, Registration ID: NCT02795065. Registered June 8, 2016.

Keywords: Bemiparin, enoxaparin, Intensive Care Unit, low-molecular-weight heparin, venous thromboembolism

\section{BACKGROUND}

Intensive care unit (ICU) patients are at a very high risk to develop venous thromboembolism (VTE) with associated significant mortality and morbidity because of their limited cardiopulmonary reserve. The incidence of VTE varies significantly among ICU population depending on the underlying disease causing the critical illness. For example, in the general ICU population, the incidence of deep venous thrombosis (DVT) is between $28 \%$ and $32 \%{ }^{[1,2]}$ whereas in trauma patients, it can reach up to $60 \%{ }^{[3]}$ or even $70 \%$ in patients with acute ischemic strokes. ${ }^{[4-6]}$ In those with hemiplegia, $1 \%-2 \%$ suffer a fatal pulmonary embolism (PE). ${ }^{[4,5]}$ The diagnosis of VTE remains generally challenging particularly in ICU patients as their clinical status such as intubation, sedation, and altered mental status usually makes it difficult to distinguish clinical symptoms of

\begin{tabular}{|l|l|}
\hline \multicolumn{3}{|c|}{ Access this article online } \\
\hline Quick Response Code: & Website: \\
& www.ijccm.org \\
\cline { 2 - 2 } & \\
&
\end{tabular}

VTE. That is why $95 \%$ of DVTs in critically ill patients are clinically silent. ${ }^{[7]}$

Due to the high prevalence and incidence of VTE in the ICU population and because ICU patients are usually from the geriatric age group with renal impairment and are susceptible for bleeding, we use low molecular weight heparin (LMWH) for DVT prophylaxis as it is safe and does not significantly influence bleeding risk in critically ill patients who have severe renal impairment. ${ }^{[8]}$

LMWHs are currently used for VTE prophylaxis. We focused our study on two LMWHs. The commonly used enoxaparin

Address for correspondence: Dr. Mohamed Sayed Abbas, Department of Anesthesia, Al Mouwasat Hospital, Dammam, Saudi Arabia. E-mail: mohamed_abasy@hotmail.com

This is an open access article distributed under the terms of the Creative Commons Attribution-NonCommercial-ShareAlike 3.0 License, which allows others to remix, tweak, and build upon the work non-commercially, as long as the author is credited and the new creations are licensed under the identical terms.

For reprints contact: reprints@medknow.com

How to cite this article: Abbas MS. Bemiparin versus enoxaparin in the prevention of venous thromboembolism among Intensive Care Unit patients. Indian J Crit Care Med 2017;21:419-23. 
a first-generation LMWH and bemiparin a second-generation LMWH. The ratio of anti-Xa to anti-IIa activity varies between bemiparin and enoxaparin (9.7 and 3.9, respectively). ${ }^{[9]} \mathrm{Few}$ studies had compared LMWHs bemiparin and enoxaparin as thromboprophylaxis following surgeries, for example, total knee replacement, vaginal, and abdominal deliveries. ${ }^{[10,11]}$

The purpose of this study is to compare the efficacy and safety of bemiparin and enoxaparin in the prevention of VTE in high-risk critically ill bedridden patients in ICU.

\section{Methods}

The study was registered on www.clinicaltrials.gov, Registration ID: NCT02795065, Registered June 8, 2016.

We conducted a prospective randomized trial to compare thromboprophylaxis using bemiparin and enoxaparin in critically ill patients in the ICU. The study was conducted between March 2014 and March 2016 and included one hundred bedridden patients in the ICU, older than 18 years, who are at high risk for developing VTE and require long term anticoagulation. Patients were determined to be at high risk for VTE if they had a diagnosis of sepsis, stroke, major burn, respiratory failure, traumatic brain injury, malignancy, and post-arrest who are intubated and mechanically ventilated on continuous intravenous sedation. All patients were initially screened on ICU admission by bilateral lower limb venous duplex before enrollment in the study, and all patients were placed on mechanical DVT prophylaxis.

Exclusion criteria from the study included hypersensitivity to LMWHs, hypercoagulability, congenital or acquired bleeding disorder, prolongation of activated partial thromboplastin time or prothrombin time by $20 \%$ compared to normal values; thrombocytopenia (platelet count $<100,000 / \mathrm{mm}^{3}$ ); macroscopic hematuria; uncontrolled hypertension (systolic blood pressure $>200 \mathrm{mmHg}$; diastolic blood pressure $>100 \mathrm{mmHg}$ ); impaired kidney function: Serum creatinine $>2.0 \mathrm{mg} / \mathrm{dL}$, bleeding gastrointestinal ulcer. Patients having a current episode of DVT or even history of prior DVT or pulmonary embolism, history of documented or suspected heparin-induced thrombocytopenia, ischemic stroke, history of or active intracranial disorder (cerebral vascular aneurysm, arterio-venous malformation or cerebral neoplasm), and history of hemorrhagic stroke, active hemorrhage or increased risk of bleeding due to impaired hemostatics or organ lesion.

Written informed consent had been obtained, and the protocol was approved by the institution.

We divided these patients into two groups each one includes 50 patients. One group received bemiparin 3500 IU subcutaneous (SC) once daily, and the other group received enoxaparin $40 \mathrm{mg} \mathrm{SC}$ once daily as a prophylaxis against thromboembolism.

Patients were followed up for 60 days after initiation of anticoagulant therapy for the development of DVT, pulmonary embolism and complications related to the injected anticoagulant. DVT was suspected if the patient had clinical symptoms of DVT and detected using bilateral lower limb venous duplex done twice weekly by the same radiologist over 60 days. The best evaluation of different lower extremities veins is obtained using different ultrasound techniques. The most commonly used method is the compression ultrasound which is used mainly for examining proximal deep veins, specifically the common femoral, femoral, and popliteal veins while the distal calf veins and the iliac veins are examined using duplex ultrasound and color Doppler. ${ }^{[12]}$ Pulmonary embolism was detected clinically by hypotension, tachycardia, hypoxemia, and decreased end-tidal carbon dioxide ${ }^{[13]}$ and confirmed radiologically by the presence of a large or a partial central filling defect in computed tomography $(\mathrm{CT})$ pulmonary angiography. ${ }^{[14]}$ Participants were followed up daily for complications related to the injected anticoagulant including any ecchymosis or hematomas developed at the site of anticoagulant injection, the presence of major bleeding defined as decrease in hemoglobin levels by $2 \mathrm{~g} / \mathrm{L}$ or more or requiring transfusion of 2 or more units of packed red cells or whole blood, the presence of minor bleeding defined as any bleeding other than major bleeding events, drop in the platelet count and the presence of allergic skin reactions or urticaria, If any of these complications was observed, the anticoagulant was immediately discontinued.

\section{Statistical analysis}

Data were collected, coded, tabulated, and then analyzed using Minitab $^{\circledR} 16$ computer software. Numerical variables were presented as a mean and standard deviation and then analyzed using Student's $t$-test. Categorical variables were presented as frequency and percentage and analyzed using Chi-square test or Fisher's exact test as appropriate. Any difference with the value of $P<0.05$ was considered statistically significant

Sample size estimation revealed that at least 50 patients are needed in each group to detect at least $60 \%$ reduction in the proportion of confirmed DVT in a patient receiving bemiparin as compared to those receiving enoxaparin, assuming the later is about $37 \% \%^{[11]}$ at a power of 0.8 and significance level of 0.05 .

\section{RESULTS}

No significant statistical differences were observed between both groups with respect to age, weight, height, gender, body mass index, and the underlying risk factors for VTE development [Table 1].

Documented DVT detected by bilateral lower limb venous duplex was observed more frequently in the enoxaparin group (ten patients [20\%] compared with two patients (4\%) in the bemiparin group) with $P<0.05$. Documented PE detected by CT pulmonary angiography was observed in seven patients $(14 \%)$ in the enoxaparin group (six patients were from the ten patients with documented DVT) with no recorded cases of confirmed PE in the bemiparin group $(P<0.05)$. No deaths were reported at 60 days follow-up for either group [Table 2]. A flow chart of the trial is illustrated in Figure 1. 
Concerning adverse effects and complications related to the injectant anticoagulant, ecchymosis or hematoma at the

\begin{tabular}{lccc}
\hline $\begin{array}{l}\text { Table 1: Patients demographic data and risk factors for } \\
\text { venous thromboembolism }\end{array}$ & \begin{tabular}{l} 
\\
\multicolumn{4}{c}{ Bemiparin } \\
$(\boldsymbol{n = 5 0 )}$
\end{tabular} & $\begin{array}{c}\text { Enoxaparin } \\
(\boldsymbol{n}=\mathbf{5 0})\end{array}$ & $\boldsymbol{P}$ \\
\hline Mean age (SD), years & $72.5(6.5)$ & $70.9(5.4)$ & 0.184 \\
Males, $n$ (\%) & $30(60)$ & $32(64)$ & 0.837 \\
Mean weight (SD), kg & $77(7.5)$ & $78.2(10.0)$ & 0.499 \\
Height (SD), cm & $160(7.7)$ & $162(7.9)$ & 0.203 \\
Body mass index (SD), kg m* & $30.1(3.9)$ & $29.8(5.7)$ & 0.759 \\
Respiratory failure, $n(\%)$ & $10(20)$ & $8(16)$ & 0.795 \\
Septic shock, $n(\%)$ & $12(24)$ & $15(30)$ & 0.652 \\
Cerebral stroke, $n(\%)$ & $8(16)$ & $11(22)$ & 0.610 \\
Traumatic brain injury, $n(\%)$ & $6(12)$ & $8(16)$ & 0.773 \\
Postarrest, $n(\%)$ & $10(20)$ & $7(14)$ & 0.594 \\
Malignancy, $n(\%)$ & $2(4)$ & $1(2)$ & 1.000 \\
Major burn, $n(\%)$ & $2(4)$ & 0 & 0.475 \\
\hline
\end{tabular}

*The body mass index is the weight in kilograms divided by the square of the height in meters. SD: Standard deviation

\begin{tabular}{lccc}
\hline \multicolumn{4}{c}{ Table 2: Analysis of the efficacy endpoints } \\
\hline & $\begin{array}{c}\text { Bemiparin } \\
(\boldsymbol{n}=\mathbf{5 0}), \boldsymbol{n}(\%)\end{array}$ & $\begin{array}{c}\text { Enoxaparin } \\
(\boldsymbol{n}=\mathbf{5 0}), \boldsymbol{n}(\%)\end{array}$ & $\boldsymbol{P}$ \\
\hline Confirmed DVT & $2(4)$ & $10(20)$ & 0.0312 \\
Confirmed PE & 0 & $7(14)$ & 0.019 \\
Death & 0 & 0 & - \\
\hline
\end{tabular}

DVT: Deep venous thrombosis; PE: Pulmonary embolism injected site was observed in 8 patients $(16 \%)$ in the enoxaprin group compared with one patient $(2 \%)$ in the bemiparin group $(P<0.05)$ with no significant statistical difference as regards other adverse effects and complications related to the injectant anticoagulant [Table 3].

All patients were followed up for 60 days with no recorded loss of follow-up for any participant.

\section{Discussion}

Critically ill patients in ICU possess multiple VTE risk factors as most of ICU patients are bedridden, sedated on mechanical ventilation with the hemodynamic instability that requires invasive procedures such as central venous line insertion to administer vasoactive medications to maintain the blood pressure and tissue perfusion. Such invasive procedures and vasoactive medications make them highly susceptible for venous thrombosis. ${ }^{[15,16]}$ Underlying diseases causing the critical illness among ICU population also increase the risk for VTE such as acute myocardial infarction, stroke, and sepsis which acts through activation of the coagulation cascade. ${ }^{[17]}$ From that, we conclude that the ICU population is always at high risk for VTE that will alert us to start them on prophylactic anticoagulation unless there is a strong contraindication. The earlier we start patients on prophylactic anticoagulation, the less the possibility for them to develop DVT with all its subsequent life-threatening complications. Hence on ICU admission, all critical care patients should be immediately assessed for and prescribed VTE prophylaxis because it can

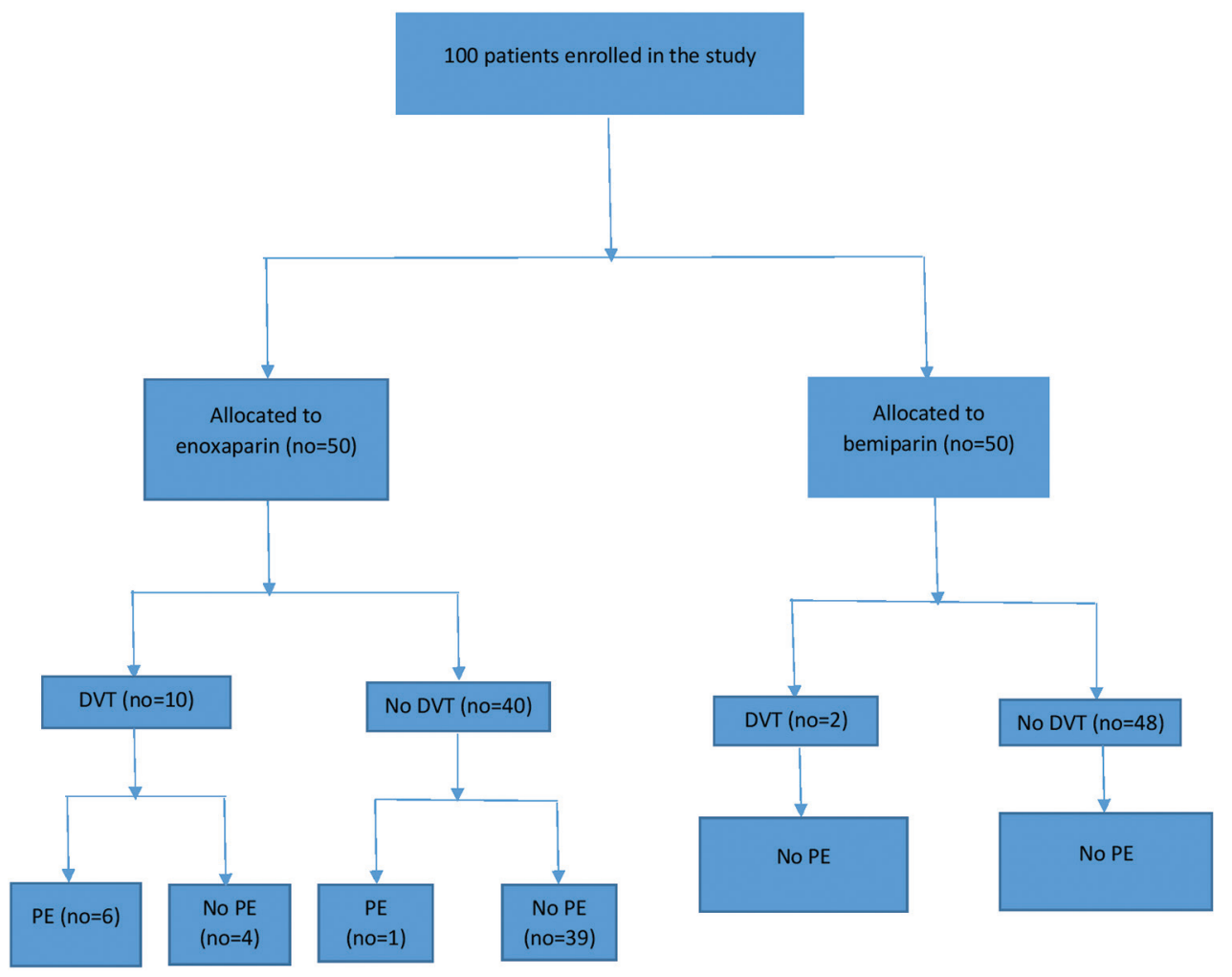

Figure 1: Flow chart of the trial 


\begin{tabular}{lccc}
\hline \multicolumn{4}{l}{ Table 3: Side effects and complications } \\
\hline & $\begin{array}{l}\text { Bemiparin } \\
(\boldsymbol{n = 5 0 )}, \boldsymbol{n}(\%)\end{array}$ & $\begin{array}{c}\text { Enoxaparin } \\
(\boldsymbol{n}=\mathbf{5 0}), \boldsymbol{n}(\%)\end{array}$ & $\boldsymbol{P}$ \\
\hline Ecchymosis or hematoma & $1(2)$ & $8(16)$ & 0.036 \\
Urticaria, allergy & 0 & 0 & - \\
Major bleeding & 0 & 0 & - \\
Minor bleeding & $4(8)$ & $5(10)$ & 1.000 \\
Drop in platelet count & $6(12)$ & $8(16)$ & 0.773 \\
\hline
\end{tabular}

significantly reduce VTE occurrence, complications, ICU stay and costs related to VTE treatment.

In this study, we compared enoxaparin, which is one of most common LMWH used in ICU, with bemiparin in the prophylaxis against VTE in critically ill high-risk ICU patients with multiple comorbidities as to our knowledge, no study has compared the safety and efficacy of these drugs in this patient population. We found that bemiparin use was associated with less incidence of DVT and pulmonary embolism and less adverse local complications at the injection site such as hematomas and ecchymosis. This increase in local injection site reactions may be attributed to bemiparin's higher factor Xa-IIa ratio compared to enoxaparin, ${ }^{[9]}$ with no significant difference as regards as thrombocytopenia and bleeding complications.

Few studies had compared both LMWH bemiparin and enoxaparin as thromboprophylaxis following surgeries. One study compared both LMWHs as postoperative thromboprophylaxis following vaginal and abdominal deliveries and found that bemiparin was as effective as enoxaparin with a lower incidence of symptomatic VTE and local side effects such as pain and ecchymosis compared with the enoxaparin group. There were no recorded cases of wound complications in the bemiparin group such as wound dehiscence, separation and hematoma compared with six recorded cases in the enoxaparin group. ${ }^{[10]}$

Another study was conducted on patients undergoing total knee replacement and compared both LMWH as regards efficacy and safety in postsurgical prevention of VTE. The study concluded that bemiparin given $6 \mathrm{~h}$ after surgery, was associated with a lower incidence of VTE (proximal DVT and $\mathrm{PE}$ ) as compared with enoxaparin given $12 \mathrm{~h}$ before surgery. There was no significant difference between both groups as regards the safety parameters. ${ }^{[1]}$

High-risk patients in the ICU should receive the appropriate dose of anticoagulation in order ensure full protection against VTE. One study conducted on cancer patients to check which is the optimal dosing of bemiparin as prophylaxis against VTE. It was found that bemiparin $3500 \mathrm{IU} /$ day administered to patients at high risk of VTE fully prevented documented symptomatic VTE, whereas three high-risk patients experienced a VTE event while receiving $2500 \mathrm{IU} /$ day bemiparin dose, recommended for patients with a moderate risk of VTE. In addition, there was no significant difference between low and high bemiparin prophylactic doses as regards bleeding rates. Thus, all high-risk patients for VTE should receive an only bemiparin dose of $3500 \mathrm{IU} /$ day to ensure full protection against VTE as no studies supporting the use of bemiparin $2500 \mathrm{IU}$ in such group of high-risk patients. ${ }^{[18]}$

Several studies demonstrated safety and efficacy of bemiparin, whereas cost analyses show the economic benefits of bemiparin treatment as compared to other heparins. ${ }^{[19]}$

The higher incidence of DVT and PE in patients treated with enoxaparin $40 \mathrm{mg} \mathrm{SC}$ once daily would indicate that the already known and commonly used enoxaparin prophylactic dosage (40 mg SC daily dose) may be inadequate to provide VTE prophylaxis. ${ }^{[20,21]}$

Limitations of this study included small sample size and single centered study which supports the need for a large randomized controlled trial.

\section{Conclusion}

Bemiparin was superior to enoxaparin as a prophylactic anticoagulant for VTE in critically ill patients with less adverse local complications at the injection site.

\section{Financial support and sponsorship}

Nil.

\section{Conflicts of interest}

There are no conflicts of interest.

\section{RefEREnCES}

1. Cade JF. High risk of the critically ill for venous thromboembolism. Crit Care Med 1982;10:448-50.

2. Fraisse F, Holzapfel L, Couland JM, Simonneau G, Bedock B, Feissel M, et al. Nadroparin in the prevention of deep vein thrombosis in acute decompensated COPD. The Association of Non-University Affiliated Intensive Care Specialist Physicians of France. Am J Respir Crit Care Med 2000;161(4 Pt 1):1109-14.

3. Attia J, Ray JG, Cook DJ, Douketis J, Ginsberg JS, Geerts WH. Deep vein thrombosis and its prevention in critically ill adults. Arch Intern Med 2001;161:1268-79.

4. McCarthy ST, Turner JJ, Robertson D, Hawkey CJ, Macey DJ. Low-dose heparin as a prophylaxis against deep-vein thrombosis after acute stroke. Lancet 1977;2:800-1.

5. Kelly J, Rudd A, Lewis R, Hunt BJ. Venous thromboembolism after acute stroke. Stroke 2001;32:262-7.

6. McCarthy ST, Turner J. Low-dose subcutaneous heparin in the prevention of deep-vein thrombosis and pulmonary emboli following acute stroke. Age Ageing 1986;15:84-8.

7. Crowther MA, Cook DJ, Griffith LE, Devereaux PJ, Rabbat CC, Clarke FJ, et al. Deep venous thrombosis: Clinically silent in the Intensive Care Unit. J Crit Care 2005;20:334-40.

8. Schulman S, Beyth RJ, Kearon C, Levine MN. Hemorrhagic complications of anticoagulant and thrombolytic treatment: American College of Chest Physicians Evidence-Based Clinical Practice Guidelines ( $8^{\text {th }}$ Edition). Chest 2008;133 6 Suppl:257S-98S.

9. Cosmi B, Palareti G. Old and new heparins. Thromb Res 2012;129:388-91.

10. Alalaf SK, Jawad RK, Muhammad PR, Ali MS, Al Tawil NG. Bemiparin versus enoxaparin as thromboprophylaxis following vaginal and abdominal deliveries: A prospective clinical trial. BMC Pregnancy Childbirth 2015;15:72.

11. Navarro-Quilis A, Castellet E, Rocha E, Paz-Jiménez J, Planès A; Bemiparin Study Group in Knee Arthroplasty. Efficacy and safety of 
bemiparin compared with enoxaparin in the prevention of venous thromboembolism after total knee arthroplasty: A randomized, double-blind clinical trial. J Thromb Haemost 2003;1:425-32.

12. Zierler BK. Ultrasonography and diagnosis of venous thromboembolism. Circulation 2004;109 12 Suppl 1:I9-14.

13. Desciak MC, Martin DE. Perioperative pulmonary embolism: Diagnosis and anesthetic management. J Clin Anesth 2011;23:153-65.

14. Wittram C, Maher MM, Yoo AJ, Kalra MK, Shepard JA, McLoud TC. $\mathrm{CT}$ angiography of pulmonary embolism: Diagnostic criteria and causes of misdiagnosis. Radiographics 2004;24:1219-38.

15. Ibrahim EH, Iregui M, Prentice D, Sherman G, Kollef MH, Shannon W. Deep vein thrombosis during prolonged mechanical ventilation despite prophylaxis. Crit Care Med 2002;30:771-4.

16. Cook D, Crowther M, Meade M, Rabbat C, Griffith L, Schiff D, et al. Deep venous thrombosis in medical-surgical critically ill patients: Prevalence, incidence, and risk factors. Crit Care Med 2005;33:1565-71.

17. Dalen JE. Pulmonary embolism: What have we learned since
Virchow? Natural history, pathophysiology, and diagnosis. Chest 2002;122:1440-56.

18. Balibrea JL, Altimiras J, Larruzea I, Gómez-Outes A, Martínez-González J, Rocha E; Bemiparin Cooperative Study Group in Surgery for Cancer. Optimal dosing of bemiparin as prophylaxis against venous thromboembolism in surgery for cancer: An audit of practice. Int J Surg 2007;5:114-9.

19. Ciccone MM, Cortese F, Corbo F, Corrales NE, Al-Momen AK, Silva A, et al. Bemiparin, an effective and safe low molecular weight heparin: A review. Vascul Pharmacol 2014;62:32-7.

20. Robinson S, Zincuk A, Strøm T, Larsen TB, Rasmussen B, Toft P. Enoxaparin, effective dosage for Intensive Care patients: Double-blinded, randomised clinical trial. Crit Care 2010;14:R41.

21. Robinson S, Zincuk A, Larsen UL, Ekstrøm C, Nybo M, Rasmussen B, et al. A comparative study of varying doses of enoxaparin for thromboprophylaxis in critically ill patients: A double-blinded, randomised controlled trial. Crit Care 2013;17:R75. 